\title{
Exposição ao Vivo no Tratamento de Agorafobia: \\ Relato de Caso
}

Resumo: Relato de caso, em que a Exposição ao Vivo foi utilizada no tratamento de paciente com diagnóstico de agorafobia. O tratamento foi realizado em doze sessões, apresentando êxito no uso dessa técnica comportamental.

Palavras Chave: Agorafobia, Exposição ao Vivo, tratamento comportamental.

Abstract: Case report, in wich case the Exposure In Vivo was used in the treatment of a patient with diagnosis of agoraphobia. The treatment was in twelve sessions, with sucess in the use of this behavioral technique. Key Words: Agoraphobia, Exposure in Vivo, behavioral treatment.

\section{Gustavo J. Fonseca D'El Rey}

\section{Psicólogo. Especialista em Psicologia Hospitalar pelo Hospital das Clínicas da FMUSP. \\ Aprimoramento em Psicopatologia Geral pela USJT-SP.}

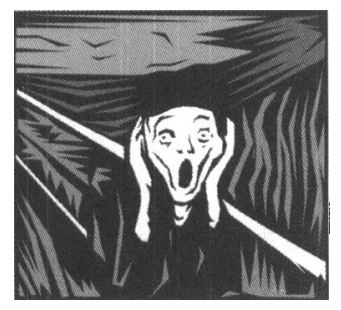

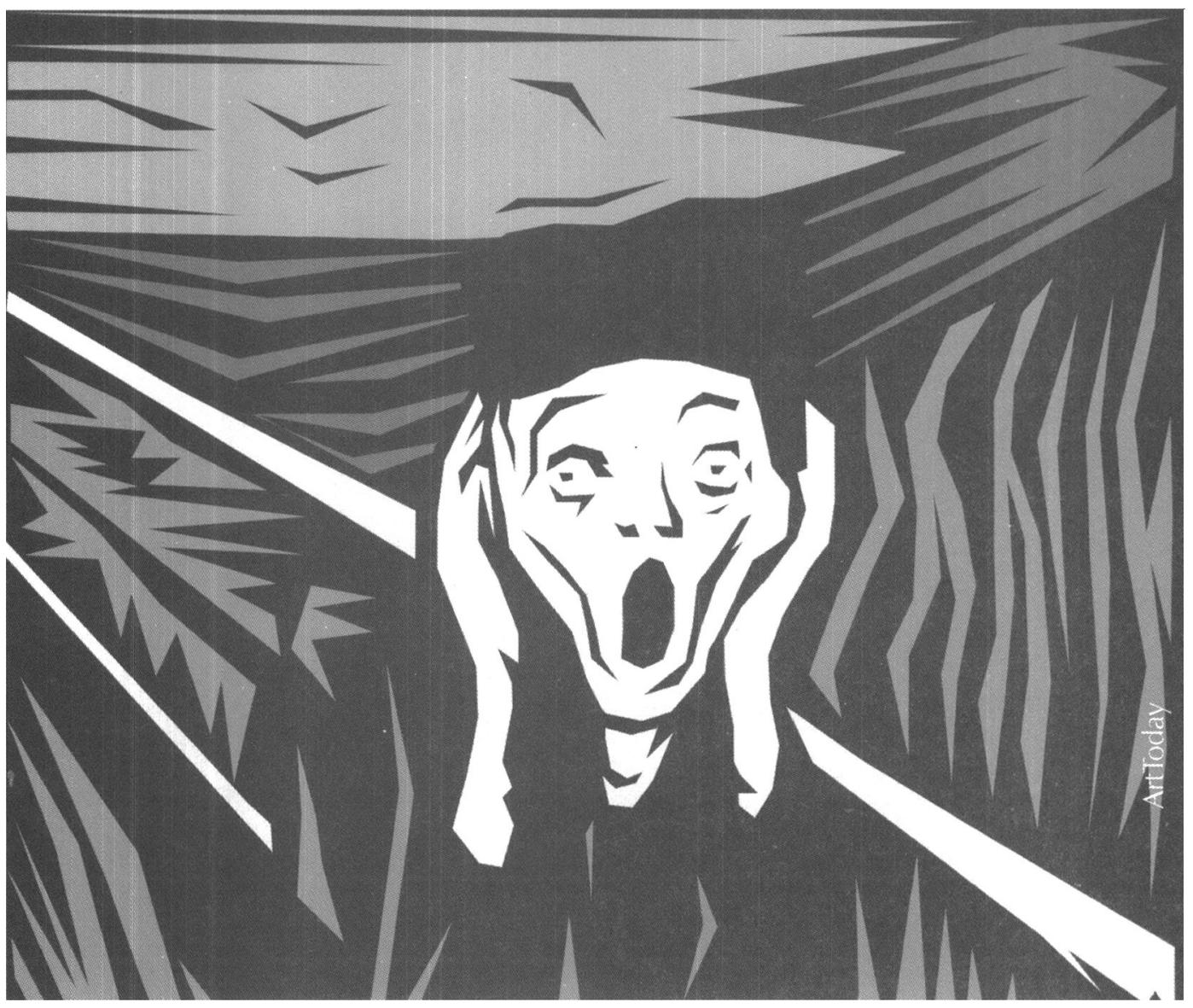

Conforme a CID-10 (OMS, 1993), o termo agorafobia refere-se ao medo de sair de casa, de lugares públicos, de multidões ou de viajar sozinho em trens, carros, ônibus ou aviões. A falta de uma saída ou ajuda disponível, é um aspecto-chave do transtorno. Esse é o mais incapacitante dos transtornos fóbicos, fazendo com que alguns pacientes fiquem completamente confinados ao lar. Na ausência de um tratamento eficaz, a agorafobia freqüentemente se torna crônica. No diagnóstico de agorafobia, pode estar presente ou não o transtorno de pânico.
Segundo Fyer, Mannuzza \& Coplan (1999), a prevalência da agorafobia na população geral ao longo da vida é de 2,5 a 6,5\%. Em populaçōes clínicas, a agorafobia quase nunca é vista sem uma história concomitante de ataques ou transtorno de pânico.

A técnica comportamental de Exposição ao Vivo implica uma exposição direta e graduada aos objetos ou situações temidas, e, na maioria das vezes, não se utiliza uma técnica de relaxamento. Paciente e terapeuta constroem uma lista 
hierárquica, que abrange as situações temidas pelo paciente. Inicia-se a técnica com o paciente se expondo ao item que provoca menos ansiedade, movendo-se para o item que provoca mais ansiedade. É importante que o paciente, para avançar na hierarquia, sinta-se seguro e confiante sobre o controle das situaçôes anteriores, mantendo, dessa forma, a crença de que pode conseguir seu objetivo final (Turner, 1996).

Conforme diversos estudos, a Exposição ao Vivo é comprovadamente um tratamento eficaz para a agorafobia (Fava et al., 1995; Basoglu, et al., 1994; Marks et al., 1993; Ghosh \& Marks, 1987; Telch et al., 1985; O'Brien \& Barlow, 1984; Jansson \& Öst, 1982; Greist et al., 1980; Zitrin et al., 1980).

\section{Resumo da História Clínica}

Paciente do sexo masculino, solteiro, com 23 anos de idade, digitador, natural e residente na cidade de São Paulo-SP com os pais e um irmão mais novo.

Em setembro de 1999, estava o paciente andando pelas imediações de sua residência quando subitamente notou seu coração acelerado, sudorese intensa, boca seca, falta de ar e dores no peito; desesperou-se achando que iria ter um "infarto". Foi, levado por sua mãe ao pronto socorro, e após exames físicos sem anormalidades, o médico plantonista medicou o paciente com diazepan e explicou que "havia sido uma crise de ansiedade", liberando-o em seguida.

Após dois dias, o paciente estava saindo de sua casa para o trabalho quando teve outra "crise". Foi levado, mais uma vez, ao pronto socorro. Novamente, os exames físicos não apresentaram alterações. Foi, então, encaminhado para consulta com psiquiatra. O paciente se negou a ir à consulta psiquiátrica.

Durante as duas semanas seguintes, teve diversas "crises", desenvolvendo com elas o medo de ficar em casa e sair sozinho por acreditar que não seria socorrido adequadamente caso precisasse. Foi marcada consulta com psiquiatra que, após avaliação, fez o diagnóstico de transtorno de pânico com agorafobia, medicando o paciente com clomipramina e ensinando-lhe técnicas de controle da respiração durante os ataques. Devido à agorafobia ser grave, foi afastado do trabalho, sendo encaminhado ao Auxílio-Doença do INSS.

Após dois meses e meio de tratamento medicamentoso e controle da respiração, o paciente não apresentava mais os ataques de pânico, ficando sozinho em casa sem problemas; porém, evitava sair de sua residência sozinho, mesmo para ir até a esquina, e somente o fazia na companhia de um familiar.

Devido a não sair sozinho de casa, foi encaminhado para tratamento comportamental em consultório particular. Foram marcadas duas sessões por semana.

\section{Síntese do Tratamento}

1ํ. Sessão: Foi realizada a coleta da história clínica. Após explicação, foi solicitado que o paciente preenchesse a Escala de Problemas e Objetivos (Anexo), onde foi definido como principal problema o medo de sair sozinho de casa, apresentando escore na Escala de Esquiva = 8 e na Escala de Medo $=7$. Cabe ressaltar que o paciente vinha acompanhado às consultas por sua mãe.

20 $\mathbf{2}^{\boldsymbol{a}}$ Sessão: Foram explicadas as principais bases do tratamento comportamental para agorafobia. Elaborou-se com o paciente uma lista hierárquica de situações temidas, atribuindo-se notas de 0 a 10 para cada uma delas, de acordo com a ansiedade que o paciente acreditava que iria sentir. A nota 0 seria equivalente a sentir-se bem, e a nota 10 seria equivalente a estar em pânico. Comentouse com o paciente que a Exposição ao Vivo deveria ser realizada várias vezes durante a semana, permanecendo na situação temida por aproximadamente 60 minutos. Como tarefa, foi combinado com o paciente, que ele tentaria se expor ao primeiro item da lista até a próxima consulta.

Escala de Problemas e Objetivos, com escore da Escala de Esquiva $=8$ e Escala de Medo $=7$ (preenchido pelo paciente no início de todas as consultas):

\section{Hierarquia da Exposição ao Vivo ${ }^{1}$ :}

4. Ficar em frente da minha casa $=2$;

4aminhar até a banca de jornais na esquina $=3$;

4 Caminhar pelo quarteirão $=4$;

. Caminhar até o supermercado, a três quarteirões da $\operatorname{minh}$ a casa $=5$;

Ir à casa de um amigo, a cinco quarteirões da minha casa $=6$;

Ir até a praça, a um quilômetro e meio de casa $=8$;

- Ir até o banco, a três quilômetros de casa $=10$;
1 Dois medos elou fobias são descritos como problemas principais. Cada um é avaliado em escala de 0 a 8 , em relação ao grau de esquiva fóbica; a soma dos dois resulta em um escore que varia de o a $1600=$ nāo evita, $4=$ evita pouco, 8 $=$ evita moderadamente, $12=$ evita acentuadamente e $16=$ evita sempre) e em relaçāo à intensidade do medo, a soma dos dois também produz um escore de 0 a $1610=\mathrm{sem}$ medo, $4=$ pouco medo, $8=$ medo moderado, $12=$ medo acentuado $e 16=$ medo extremo). A escala pode ser preenchida pelo proprio paciente após explicaçâo. No presente estudo, como o paciente apresentava apenas um problema (näo sair de casa sozinho), optou-se por uma modificaçáo na escala utilizada, ou seja, o valor total do escore de esquiva variou de o a $810=$ náo evita, 2 = evita pouco, $4=$ evita moderadamente, $6=$ evita acentuadamente e $8=$ evita sempre) e o valor total do escore de medo também variou de o a $810=$ sem medo, $2=$ pouco medo, $4=$ medo moderado, 6 $=$ medo acentuado $e 8=$ medo extremo). 
3 3 a sessão: O paciente disse estar muito feliz, pois havia conseguido ficar em frente a sua casa sozinho. Explicou-se ao paciente que, ao entrar em contato com a situação geradora de ansiedade, a pessoa experimenta a princípio um aumento da mesma, até atingir um patamar máximo de intensidade, que se mantém. Após algum tempo, ocorre o decréscimo da ansiedade, ou seja, a habituação. E que os patamares de ansiedade, provavelmente, seriam menores quanto maior a freqüência com que ele se expusesse às situações temidas. Solicitou-se ao paciente que se expusesse ao segundo item da hierarquia, pois o primeiro não the causava mais desconforto.

Escala de Problemas e Objetivos, com escore da Escala de Esquiva $=7$ e Escala de Medo $=6$.

4a 4 a Sessão: O paciente relatou que sua ansiedade havia diminuído em relação ao segundo item. Comentou, ainda, ter notado que, ao diminuir a ansiedade do segundo item através da exposição, a nota que havia dado ao terceiro item também havia diminuído; em vez de 4, a nota era 2 . Explicou-se que isso era esperado, pois, dessa maneira, ao se chegar ao último item, provavelmente a nota não seria mais 10 , e que ele seria capaz de enfrentar uma situação que antes parecia impossível. Foi discutido com o paciente o espaçamento das consultas para uma vez por semana, devido a sua melhora e por sentir-se mais confiante. Foi solicitado que se expusesse ao terceiro e quarto itens da hierarquia durante a semana.

Escala de Problemas e Objetivos, com escore da Escala de Esquiva $=6$ e Escala de Medo $=5$.

- 5a Sessão: Não apresentou problemas na realização da tarefa de exposição, durante a semana. Comentou que estava indo sozinho para a casa de amigos que moravam a três quarteiróes de sua casa. Como tarefa para a semana, foi solicitado que realizasse a exposição aos itens 5 e 6.

Escala de Problemas e Objetivos, com escore da Escala de Esquiva $=4$ e Escala de Medo $=4$.

6 6 Sessão: Relatou que o quinto item não mais o incomodava, porém ainda sentia ansiedade e desconforto na realização do sexto item. Atribuiu nota 5 a esse item. Comentou-se que isto poderia ocorrer, e que durante a semana, o paciente poderia voltar a realizar este item através da exposição. Solicitou-se que realizasse apenas o sexto item da hierarquia como tarefa.

Escala de Problemas e Objetivos, com escore da Escala de Esquiva $=4$ e Escala de Medo $=4$.

7ํ. Sessão: O paciente disse estar muito orgulhoso de si mesmo, pois havia conseguido se expor ao sexto item, e a ansiedade causada por ele não mais o incomodava. Questionou-se com o paciente qual o grau de ansiedade que ele imaginava iria sentir no sétimo item, pois no início do tratamento esse item the parecia impossível de ser realizado. Acreditava, agora, que a nota para esse item seria 4 , e não mais 10. Para a semana, foi solicitado que realizasse a exposição para o sétimo item, ou seja, o último da hierarquia.

\section{Escala de Problemas e Objetivos, com escore da Escala de Esquiva $=2$ e Escala de Medo $=2$.}

4a Sessão: Nessa consulta, o paciente veio sozinho, ou seja, sem sua mãe. Comentou que havia se exposto ao sétimo item sem problemas. Comentou também que havia ido sozinho de carro à casa de alguns amigos. Foi solicitado que, durante a semana, ele tentasse ir para lugares distantes, de carro, a pé, de ônibus etc. Escala de Problemas e Objetivos, com escore da Escala de Esquiva $=1 \mathrm{e}$ Escala de Medo $=1$.

4a - Sessão: O paciente comentou que estava saindo para lugares distantes de sua casa sem problemas. Disse que havia recebido alta do INSS e voltado a trabalhar, estando muito feliz por isso. Explicou-se sobre a importância do paciente continuar a se expor às situaçōes, não se esquivando delas, para que a melhora conseguida até o momento se mantivesse. Em acordo com o paciente, foi marcada a próxima consulta com intervalo de 21 dias. Escala de Problemas e Objetivos, com escore da Escala de Esquiva $=0 \mathrm{e}$ Escala de Medo $=1$.

10 $10^{\text {a }}$ Sessão: $O$ paciente comentou sobre uma viagem que havia realizado para a casa de campo de um amigo, no intervalo de 21 dias, não ocorrendo problemas. Foi marcada nova consulta para daí a 30 dias. Escala de Problemas e Objetivos, com escore da Escala de Esquiva $=0$ e Escala de Medo $=0$.

11 11 Sessão: Não ocorreram problemas durante o intervalo de 30 dias. Foi discutido com o paciente que, se sua melhora se mantivesse até a próxima consulta, receberia alta do tratamento psicológico. Foi marcada nova consulta para daí a 60 dias.

Escala de Problemas e Objetivos, com escore da Escala de Esquiva $=0$ e Escala de Medo $=0$.

12 12 Sessão: Comentou que havia realizado diversas viagens sozinho, e que não evitava mais nenhuma situação, como no início do tratamento. De comum acordo, nessa consulta foi dada alta ao paciente.

Escala de Problemas e Objetivos, com escore da Escala de Esquiva $=0$ e Escala de Medo $=0$.

Contato telefônico: Após oito meses do término 
do tratamento psicológico, entrou-se em contato com o paciente. Esse, relatou que sua melhora se mantinha, dizendo "eu nem lembro que tive pânico". Comentou que seu psiquiatra havia descontinuado e suspendido o uso da clomipramina.

Para uma melhor visualização da Escala de Problemas e Objetivos, as sub-escalas de esquiva e de medo serão apresentadas na forma de gráficos:
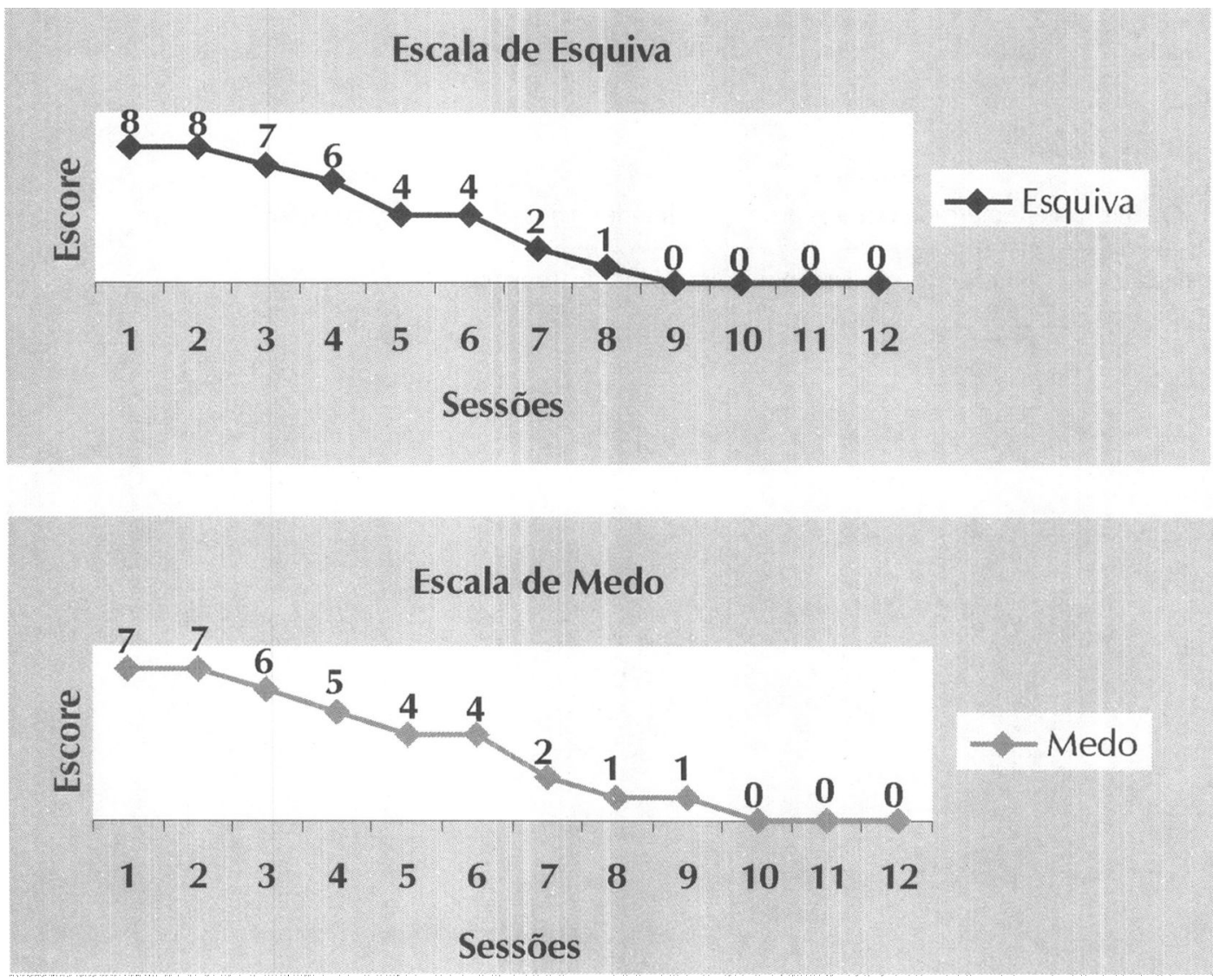

\section{Comentários}

Cabe ressaltar, nesse relato de caso, que um ponto importante no sucesso do tratamento foi a dedicação do paciente às atividades propostas, ou seja, à realização da Exposição ao Vivo.

Observando-se a Escala de Problemas e Objetivos, pode-se notar que a diminuiçāo dos escores de esquiva e medo somente aconteceram após o início da Exposição ao Vivo, ocorrendo a remissão total da esquiva na $9^{a}$ sessão, e a do medo na $10^{\text {a }}$ sessão.

O espaçamento das sessōes para 21, 30 e 60 dias, respectivamente, teve como propósito verificar a recorrência ou não dos sintomas agorafóbicos, bem como aos poucos ir "desligando" o paciente do vínculo terapêutico.

A Exposição ao Vivo se mostrou eficaz, tanto na melhora do paciente como na manutenção dessa melhora, conforme literatura pesquisada (Fava et al., 1995; Basoglu, et al., 1994; Marks et al., 1993; Chosh \& Marks, 1987; Telch et al., 1985; O’Brien \& Barlow, 1984; Jansson \& Öst, 1982; Greist et al., 1980; Zitrin et al., 1980). 
Anexo Escala de Problemas e Objetivos (Gelder \& Marks, 1966; tradução AMBAM, 1985)

Principais problemas:

1)

2)

Escala de Esquiva:

1. Quanto você evita cada um dos problemas acima, por medo das sensações ruins associadas a eles ?

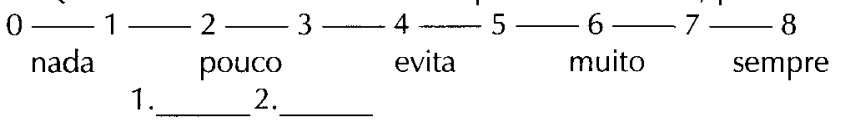

Escala de Medo:

1. Quanto você teme cada um dos problemas listados acima?

$0-1-3-5-5-6-5$
nada
$1 . \quad 2$.

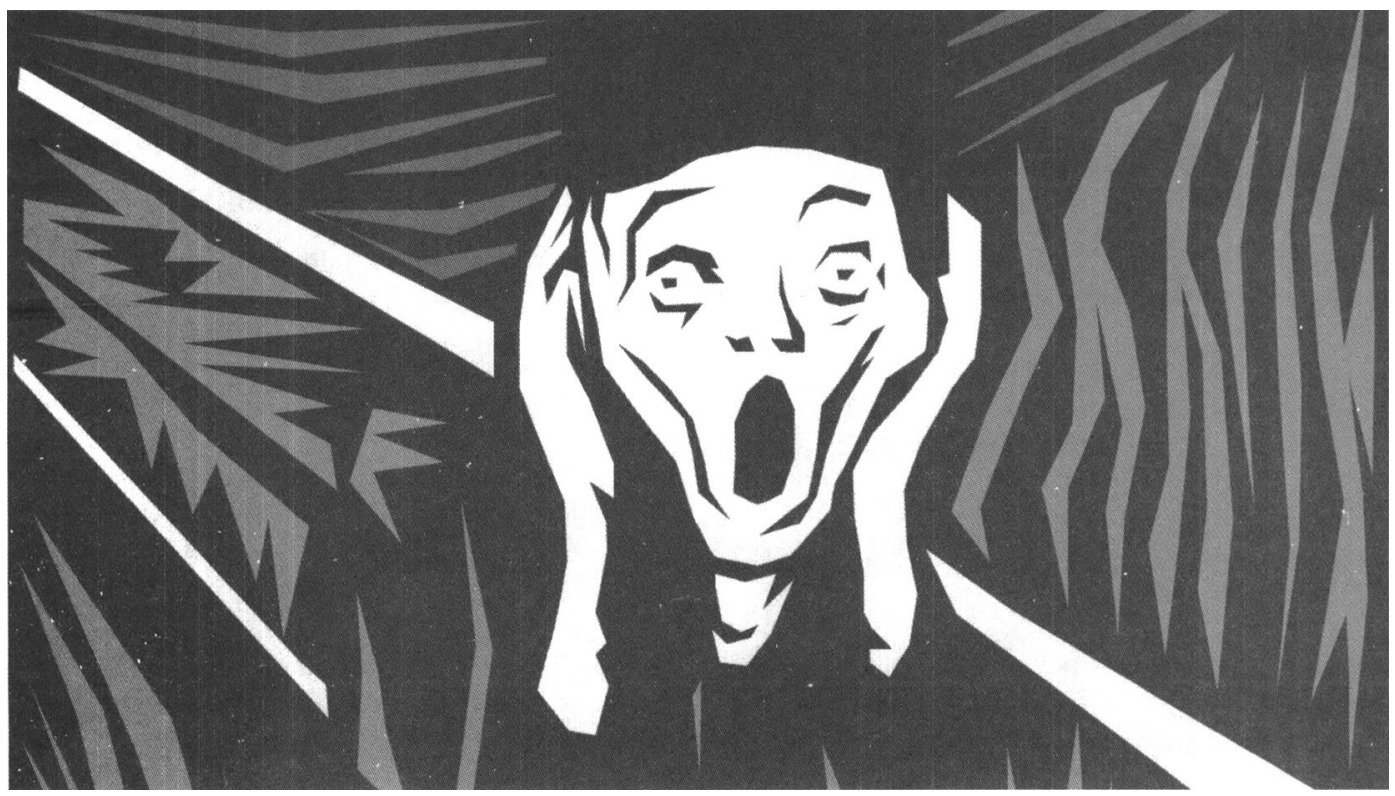


Basoglu, M.; Marks, I.M.; Kilic, C.; Noshivani, H. \& O'Sullivan, G. (1994) The Relationship Between Panic, Antecipatory Anxiety, Agoraphobia and Clobal Improvemente in Panic Disorder with Agoraphobia Treated with Alprazolan and Exposure. British Journal of Psychiatry, 164: 647-652.

Fava, G.A.; Zielezny, M.; Savron, G. \& Grandi, S. (1995). Long-term Effects of Behavioral Treatment for Panic Disorder with Agoraphobia. British Journal of Psychiatry, 166: 87-92.

Fyer, A.J; Mannuzza, S. \& Coplan, J.D. (1999). Transtorno de Pânicoe Agorafobia. Em Kaplan, H.I. \& Sadock, B.J. Tratado de Psiquiatria-Volume 2. $6^{a}$ ed. Porto Alegre: Artes Médicas.

Gelder, M.G. \& Marks, I.M. (1966). Severe Agoraphobia: AControlled Trial. British journal of Psychiatry, 112: 309-319. (Traduçāo AMBAN do IPq-HC-FMUSP, 1985).

Chosh, A. \& Marks, I.M. (1987). Self-treatment of Agoraphobia by Exposure. Behavioral Therapy, 18: 03-16.

Greist, J.H.; Marks, I.M.; Berlin, F.; Gourney, K. \& Noshirvani, H. (1980) Avoidance Versus Confrontation of Fear. Behavioral Therapy, 11:0114

Jansson, L. \& Öst, L..G. (1982). Behavioral Treatments for Agoraphobia: An Evaluative Review. Clinical Psychology Review, 2: 311-336.
Marks, I.M.; Swinson, R.P.; Basoglu, M.; Klaus, K.; Noshirvani, H.; O'Sullivan, G.; Lelliot, P.T.; Kirby, M.; McNamee, G.; Segun, S. \& Wickwire, K. (1993). Alprazolan and Exposure Alone and Combined in Panic Disorder with Agoraphobia: A Controlled Study in London and Toronto. British Journal of Psychiatry, 162: 776-787.

O'Brien, G.T. \& Barlow, D.H. (1984). Agoraphobia. Em Turner, S.M (ed.) Behavioral Treatment of Anxiety Disorders. New York: Plenum Press.

Organizaçăo Mundial de Saúde (1993). Classificação de Transtornos Mentais e de Comportamento da CID-10: Descrições Clínicas e Diretrizes Diagnósticas. Porto Alegre: Artes Médicas.

Telch, M.J.; Agras, W.S.; Taylor, C.B.; Roth, W.C. \& Gallen, C. (1985) Combined Pharmacological and Behavioral Treatment for Agoraphobia. Behavioral Research and Therapy, 23: 325-335.

Turner, R.M. (1996). A Dessensibilização Sistemática. Em Caballo, V.E. Manual de Técnicas de Terapia e Modificação do Comportamento. São Paulo: Santos Editora.

Zitrin, C.M.; Klein, D.F. \& Woerner, M.G. (1980). Treatment of Agoraphobia with Group Exposure In Vivo and Imipramine. Archives of General Psychiatry, 37: 63-72.

\section{Referências bibliográficas}

